Association for Information Systems AIS Electronic Library (AISeL)

Wirtschaftsinformatik Proceedings 2001

Wirtschaftsinformatik

September 2001

\title{
E-Disease Management - Recent Developments
}

Alin Adomeit

McKinsey\& Company, Inc., alin_adomeit@mckinsey.com

Axel Baur

McKinsey \& Company, Inc., Axel_Baur@mckinsey.com

Thomas Schmitt

WinterthurInsurance, thomas.schmitt@winterthur.com

Follow this and additional works at: http://aisel.aisnet.org/wi2001

\section{Recommended Citation}

Adomeit, Alin; Baur, Axel; and Schmitt, Thomas, "E-Disease Management - Recent Developments" (2001). Wirtschaftsinformatik Proceedings 2001.61.

http://aisel.aisnet.org/wi2001/61

This material is brought to you by the Wirtschaftsinformatik at AIS Electronic Library (AISeL). It has been accepted for inclusion in Wirtschaftsinformatik Proceedings 2001 by an authorized administrator of AIS Electronic Library (AISeL). For more information, please contact elibrary@aisnet.org. 
In: Buhl, Hans Ulrich, u.a. (Hg.) 2001. Information Age Economy; 5. Internationale Tagung Wirtschaftsinformatik 2001. Heidelberg: Physica-Verlag

ISBN: 3-7908-1427-X

(C) Physica-Verlag Heidelberg 2001 


\title{
E-Disease Management - Recent Developments
}

\author{
Alin Adomeit, Axel Baur
}

McKinsey \& Company, Inc.

\section{Thomas Schmitt}

Winterthur Insurance

Summary: Regulatory changes recently proposed by the $B M G^{l}$ are kindling renewed interest in disease management (DM) among German payors. Earlier DM efforts - mainly in the US - were discouraging, but new technologies have emerged with the potential to vastly improve DM business systems. These programs will only prevail if they are of very high quality and result in clear savings to payors while simultaneously providing clear benefit to patients. Determinants of results are improvements in medical quality/quality of life for patients, and net cost reductions in medical claims (after program-induced medical, set-up and running costs) for payors. New-generation DM programs using e-health technologies can successfully address previously intractable issues such as patient selection and compliance. Increasing program-related claims reductions at lower running costs would finally yield pay-off for payors. Experience and modelings show that net savings for payors of over $10 \%$ of medical claims incurred for the respective populations are feasible with programs combining high medical competence, smart use of technology and operational excellence. In a market that could reach revenues of $€ 500$ million (p.a.) in Germany in 2010, this offers exciting opportunities both for technology providers that directly address German payors and fullservice disease management companies. Size will be critical, and there will only be a few winners. This article outlines the factors that are likely to determine success.

The findings below - although they do not represent an exhaustive description of disease management - are based on the experience of Medvantis, a €40 million investment by Wintherthur Insurance.

\footnotetext{
Bundesministerium für Gesundheit: Federal Ministry of Health
} 


\section{Disease management gets another chance}

Interest in disease management (DM) among German payors has recently revived due to regulatory changes proposed by the Ministry of Health. In April 2001 it announced plans to support statutory payors' DM efforts with a dedicated financing pool as part of an overhaul of the "Risikostrukturausgleich"2. DM programs that address one of seven chronic conditions ${ }^{3}$ and are granted accreditation will (subject to constant evaluation) receive $70 \%$ refunding of their expenditures from a joint payors' fund from 2002 on.

These planned regulatory changes are based on recent developments and findings regarding the treatment and medical claims of chronically ill patient populations, such as patients with diabetes or heart disease. Chronic disease is a major cost factor in the health care system of industrial nations. $10 \%$ of Germany's population is afflicted by either diabetes or asthma (with a spread of around 50/50). Congestive heart failure is the most common cause of hospital admissions among citizens over 65 . Strokes affect 150,000 - 200,000 people in Germany every year, and are estimated to cause direct costs of over DM 12 billion. The aging of Germany's population means the prevalence of these conditions is rising dramatically - as well as the associated costs.

While payors struggle with increasing medical expenses, evidence is accumulating that treatment of these chronic conditions is far from adequate. With diabetes, for example, specialist associations say $50 \%$ of complications such as amputation, blindness or stroke could be avoided by better monitoring and care [StVi90]. Among asthma patients, a survey showed that $80 \%$ felt insufficiently informed about their condition [Schu96]. More than half of all hospital admissions and days off work could possibly be prevented by state-of-the-art treatment of patients with asthma [MuLe01]. The economic implications of inadequate care are huge. While a well-controlled diabetic patient costs around $€ 2,000$ a year, costs for patients with complications exceed $€ 5,000$ [BaWi00]. Although there are numerous dedicated healthcare professionals and institutions in Germany (approximately 350,000 physicians and dentists, and 3,600 hospitals and clinics), institutionalized integrators of care are definitely lacking. A patient with breast cancer, for example, meets 10 to 15 different providers in the course of diagnosis and treatment, from the gynecologist and radiologist making an initial diagnosis through various hospital departments during operative and subsequent treatment to an oncologist for follow-up. At each interface there is the danger of information being lost or

2 The mechanism in operation through which all Germany's statutory payors compensate individual payors for any negative age/risk structure of the patients they Disugnoses proposed for disease management efforts according to the Lauterbach/Wille Report: Diabetes mellitus, coronary heart disease, hypertension, congestive heart failure, stroke, asthma, and breast cancer. 
delayed - e.g., on the intolerance of a certain medication. If the patient is unlucky, nobody in the whole chain takes responsibility for explaining the diagnosis and implications in detail, resulting in potential over- or undertreatment during the disease and creating fear and uncertainty in the patient.

Hopes over the last decade have been that disease management could - at least in the long run - simultaneously help improve care and control costs. After many disappointments, the breakthrough could be just around the corner.

\section{How disease management programs work}

Disease management programs supplement existing medical care structures by acting as an intermediary between patients and providers (physicians, hospitals, etc.), coordinating care and ensuring adherence to their treatment plans. Disease management can be offered by independent businesses, pharmacos, or by payors themselves. Programs comprise patient selection and acquisition processes, patient education and empowerment to manage their disease, as well as direct interaction with patients and providers to implement evidence-based care, and intervention when signs of insufficient disease control occur. DM programs ideally require comprehensive pooling and exchange of medical data, but are not meant to replace direct physician-to-patient relationships.

Congestive heart failure is a good example to demonstrate the potential benefits of DM. Imagine an average patient with severe heart failure who is admitted to hospital three times a year due to oedema of the lung. This is a life-threatening condition if not treated promptly. In a DM program, this patient would be educated by an expert to learn more about his disease, such as the importance of taking his medication or adhering to a specific diet. He would learn to monitor himself, and the DM staff together with his physician would then advise him on his medication, and on measures he should take if his weight increased over a certain limit. DM staff would regularly call him to check how he felt and encourage him to comply with his medication. This patient would then be much better off because he would be less handicapped by the disease, experiencing fewer incidences of acute deterioration. His medical expenses would also be lower because hospital admissions could be prevented or substantially reduced.

\section{Earlier setbacks...}

Renewed interest in disease management follows a phase of reservation resulting from disappointments with earlier approaches. Most of these programs, launched mainly by HMOs and pharmacos in the US in the first half of the nineties, failed to satisfy expectations and were discontinued. The reason for this was that the business models they were based on proved largely unsuccessful. Payors are un- 
derstandably hesitant to invest heavily in disease management programs unless the following issues are solved:

- Non-specific patient selection

In many cases failure was due to the fact that in the population chosen the average occurrence of a high-cost adverse event was not high enough to outweigh the cost of the DM program . In hypercholesterolemia, for example - an acknowledged risk factor for coronary artery disease that can be successfully treated medically - the risk of any affected patient actually suffering a heart attack is approximately $0.1 \%$. This means you must have one thousand patients in your program to prevent a heart attack in just one, unless you manage to select the patients most likely to suffer a heart attack.

- Excessive program costs

Patient management expenditure was often higher than expected in early disease management programs. One reason was the huge and complicated information flows required to monitor and manage patients. Obtaining the medical data necessary to judge a participant's status from various physicians, hospitals and the patients themselves was tremendously time-consuming. The second main reason was that the effort required to change patient behavior and implement evidence-based care was often underestimated. Low-intervention programs (e.g., a handful of mailings and 3 - 4 phone calls in a depression program) failed to demonstrate impact on clinical and cost outcomes. The number of patients in most programs remained too low to achieve economies of scale due to the high churn rate. In 1999, the total number of patients involved in the cardiac programs of a leading DM provider in the US involving patients from 20 large payors was estimated at only 8,000. Many other providers had considerably fewer. Even if programs had managed to attract and retain higher numbers of participants, many organizations would not have been able to handle them efficiently, i.e., at lower per patient costs, because programs were not designed for scalability.

- Low compliance

Getting patients to change diet and take their drugs regularly is a challenge, particularly in conditions that do not cause symptoms immediately, but lead to organ damage and manifest clinically much later. Generally, patient compliance with their prescribed medication is strikingly low, estimated at 30-50\% for hypertension, and $45-75 \%$ for diabetes. Programs struggled to demonstrate that compliance was superior with disease management. One facet of this was that programs often met with resistance from both patients and physicians. Patients disliked the idea of being controlled, and administered "cookbook medicine". Physicians felt new intermediaries could endanger the trust-based relationship with their patients, and so did not always fully cooperate in reinforcing compliant patient behavior. 
- Limited and delayed payoff for payors

Although preventive patient education and treatment may be worthwhile in many conditions from a macroeconomic viewpoint, decreasing the risks of disability and early retirement, such efforts will probably not pay off for a payor. Unless other benefactors like pension funds or employers share the investments with them, payors are unlikely to finance programs in diseases with a low likelihood of high-expense adverse events. In conditions like diabetes, on the other hand, the positive effects of good control may show after a just few years because future complications are highly probable. Even here, however, the programs did not catch on. A major reason was that payors could not observe the positive impact on their patients because patients in the US change health plans whenever they change employers. When a payor invests in a DM program, it is highly likely to be a competitor who benefits Overall, programs generally lacked a methodologically sound cost-benefit evaluation, which meant clear-cut evidence of payors' return on investment and patients' ultimate benefits was scant.

\section{...and new hopes}

New evidence raises hopes that disease management may fulfill the initial high expectations. Sophisticated computer simulation models for diabetes show that improved monitoring and treatment increases life expectancy while decreasing disease-related lifetime medical costs [Palm00]. Evaluation of recent DM programs indicates significantly reduced medical expenditure. In a heart failure program of Lifemasters, medical claims were reduced by $13 \%$ compared to the previous year, and by $20 \%$ compared to the control group [HeRu99].

\section{E-health connectivity technologies: Examples of online medical monitoring companies}

LifeMasters, California, has contracted with various managed-care organizations, covering approximately 15,000 subscribers with illnesses suitable for remote monitoring, mainly congestive heart failure, diabetes and asthma. In a small study, Lifemasters demonstrated that the Internet can successfully be used as a platform for the delivery of DM in an elderly population of patients with congestive heart failure. LifeChart, California, serves about 5,000 individuals suffering from asthma. Subscribers take readings on a monitoring device and upload results via a phone line to a confidential database, from which caregivers and medical personnel can access the information via a password-protected, secure Web interface. Shahal Medical Services Ltd. from Israel, listed on the Swiss stock exchange, offers monitoring for cardiac disease with a modem-connected ECG device, and has 55,000 subscribers for their 24-hour monitoring and consultation services, which include data processing, evaluation and feedback to patients. 
Programs run by Boehringer Ingelheim and by the German disease management vendor Innovacare reported similar savings for patients with severe asthma [ÄZ01]. There are now clear indications that businesses in disease management can be successful, and that much of this success will come from the innovative etechnologies that are now providing the tools to make the unappealing business models of the past workable.

\section{E-health changes the game}

Over the last few years, however, new technologies have emerged to support the patient management process. E-health, meaning the use of the Internet, telemedicine devices and mobile communication channels as well as innovative data management systems for healthcare purposes, improves patient contact, data exchange and compliance, greatly increasing both efficiency and effectiveness.

\subsection{Technology to support the workflow: Outlines of a new- generation DM program}

The disease management workflow comprises five major elements, from patient selection to program evaluation. Each step is associated with specific challenges, which have to be addressed technologically. The following description outlines the characteristics of a new-generation DM program.

- Data analysis for participant acquisition

Selecting potential participants from the insured population is very complex. Typically, the data that have to be integrated may come from very different IT systems lacking a common interface. Different payors use very different database systems and IT platforms. Available cost data also does not easily permit the identification of the target group, e.g., by allocation of disease-specific costs. The patient data should be imported into a patient data warehouse to be able to provide consecutive filtering and data capability. A sequence of data analytical steps has to filter relevant groups. In the process, additional medical information may have to be gained from patients (after obtaining their informed consent). Using Internet-based interactive risk assessment calculators or questionnaires alleviates this process by involving patients in the process of screening and participant selection. 
DISEASE MANAGEMENT WORKFLOW: REQUIREMENTS AND AVAILABLE e-HEALTH TOOLS

\begin{tabular}{|c|c|c|c|c|c|}
\hline $\begin{array}{l}\text { Process } \\
\text { steps }\end{array}$ & $\left.\begin{array}{|l}\text { Data analysis } \\
\text { for patient } \\
\text { acquisition }\end{array}\right\rangle$ & $\begin{array}{l}\text { Data acqui- } \\
\text { sition and } \\
\text { transmission }\end{array}$ & $\begin{array}{l}\text { Data } \\
\text { evaluation } \\
\text { and storage }\end{array}$ & $\begin{array}{l}\text { Remote/ on- } \\
\text { site inter- } \\
\text { vention }\end{array}$ & $\begin{array}{l}\text { Cost-benefit } \\
\text { evaluation }\end{array}$ \\
\hline $\begin{array}{l}\text { Require- } \\
\text { ments }\end{array}$ & $\begin{array}{l}\text { - Integration of } \\
\text { data from dif- } \\
\text { ferent IT sys- } \\
\text { tems } \\
\text { - Advanced } \\
\text { data analytical } \\
\text { tools } \\
\text { - Identification } \\
\text { of suitable } \\
\text { patients } \\
\text { - Setting cost } \\
\text { baseline }\end{array}$ & $\begin{array}{l}\text { - Exact and } \\
\text { reliable daily } \\
\text { measurement } \\
\text { - Convenience } \\
\text { to achieve } \\
\text { compliance } \\
\text { - Integration of } \\
\text { different } \\
\text { media } \\
\text { - Data privacy }\end{array}$ & $\begin{array}{l}\text { - Automated } \\
\text { data pre- } \\
\text { screening and } \\
\text { prioritization } \\
\text { - Database } \\
\text { access from } \\
\text { various } \\
\text { channels }\end{array}$ & $\begin{array}{l}\text { - Initiation of } \\
\text { call center/ } \\
\text { physician } \\
\text { activity } \\
\text { Information } \\
\text { and motivation } \\
\text { of patient }\end{array}$ & $\begin{array}{l}\text { Controlled, } \\
\text { ideally } \\
\text { prospective } \\
\text { study (inter- } \\
\text { vention/con- } \\
\text { trol group) }\end{array}$ \\
\hline $\begin{array}{l}\text { E-health } \\
\text { tools }\end{array}$ & $\begin{array}{l}\text { - Patient Data } \\
\text { Warehouse } \\
\text { - Internet risk } \\
\text { assessment } \\
\text { calculators } \\
\text { - Online ques- } \\
\text { tionnaires }\end{array}$ & $\begin{array}{l}\text { - Electronic patie } \\
\text { - Remote } \\
\text { monitoring } \\
\text { devices } \\
\text { - WAP/SMS } \\
\text { communication }\end{array}$ & $\begin{array}{l}\text { - Went record (EPR) } \\
\text { databased } \\
\text { systems } \\
\text { Decision- } \\
\text { Dodeling } \\
\text { systems }\end{array}$ & $\begin{array}{l}\text { - E-mail contact } \\
\text { - Online } \\
\text { education } \\
\text { - Disease-spe- } \\
\text { cific content }\end{array}$ & \\
\hline
\end{tabular}

- Data acquisition and transmission

In some conditions, tight monitoring and rapid reaction to signs of deterioration is the key to successful disease control. Gradual deterioration in a critical parameter can be monitored and counteracted by medication or lifestyle adjustments. In a traditional physician-to-patient relationship, the day-to-day monitoring necessary is just not feasible: neither patient nor physician are willing to have daily contact to check, for example, the pulmonary function of an asthmatic. Remote monitoring can be a solution for severely affected patients. Regularly transmitting one or a few critical parameters to a monitoring center is easy with devices using a modem connection to transmit data via a regular phone line. Connecting an - ideally self-activating - monitoring device can make data transmission even more convenient for patients, and they can expect timely feedback after analysis of their data.

Elderly people are the fastest growing Internet user segment in Germany, but programs relying heavily on Internet communication may still fail due to the fact that participants are reluctant to use computers to monitor their health. In a population widely used to communication via mobile phone and voicemail systems, however, SMS messaging, automated telephone systems or WAP have the potential to enable easy day-to-day data exchange with participants without PCs. Some entirely new communication devices are being developed that are simple to operate without any technology know-how at all. Health Hero network, a California based e-health company, has developed the "Health Buddy". This is a book-size communicator for daily information ex- 
change. Seventeen different healthplans and hospitals subscribe to the network service at prices of around \$1 per day per patient. Nets AG is a German example of a new entrant using WAP communication to interact with patients on their symptoms and quality of life. These communication devices can help to ensure frequent patient contact at low cost.

- Data evaluation and storage

Data analysis by the DM organization, e.g., payor or third party, and feedback to the patient provides added value. Patients cannot fully assess the data without professional help, and often feel more secure if they know they will be alerted of any critical change. Prescreening of incoming data by software using disease-specific data analysis protocols allows disease management staff to analyze patient data quickly and give fast feedback to patients requiring intervention, or to alert their physicians. Disease management operations demand a high level of adaptability and integration across channels. They must be capable of processing incoming data from various media: remote monitoring devices, SMS/WAP messages, call center messages or regular mail and FAX. Ideally, the cornerstone of DM is an electronic patient record (EPR) that stores all patient-relevant data in a database system that can be accessed over multiple channels like Internet, direct dialup, fax and even call center by everyone involved in the process: DM agents, providers and patients. The data model has to offer variability so it can be used or adapted for various disease entities, and new functionalities can be added fast as the program develops.

- Intervention (on-site/remote)

To bring about change in care and patient behavior, data evaluation has to be followed up by DM agents or physicians. Physicians can be alerted to their patients' status by semi-automated mail or fax services. Intervention algorithms clarify where immediate contact and emergency alerts (e.g., by phone) are necessary. The same applies for patients, who can be sent semi-standardized email feedback and medical information very frequently, and offered additional personal contact with their disease manager via e-mail or phone. Online education tools and specific disease-related Internet content can improve their ability to manage their condition themselves.

- Program evaluation

A fully integrated database that combines resource utilization, medical and quality of life data is the basis for a valid outcome evaluation. Monitoring cost and medical development over time may be misleading because external factors and the natural development of the disease in the cohort are difficult to model. Success could be masked by a cost increase due to other factors. Ideally, the disease management group is compared to a control group in a controlled, prospective study. Standards required for program evaluation, e.g., with respect to data security and auditing, are expected to increase over time, with prospective randomized clinical studies representing benchmarks. 
Web-based systems are much more suitable for achieving all these prerequisites than the previous generation of client/server systems. Having to connect workstations, servers and databases without a common protocol like TCP/IP was expensive, took months or years to launch, and was slow to change. Producing DM systems that require only a standard web browser or custom device to interface to applications and databases offers important new capabilities: systems are technically more flexible, and can be more easily customized, permitting shorter implementation cycles. Provider-to-provider and doctor-to-patient (or disease-managerto-patient) communication becomes far easier.

\section{Opportunities opening up for a sustainable business model}

Payors naturally benefit from successful disease management efforts. They will, of course, only be prepared to continuously invest in these programs if the investment does pay off - at an improved or at least constant level of medical care. Ehealth technology looks set to make this possible. The DM business model is beginning to seem viable at last.

\subsection{Producing net savings for payors}

In this setting, the basic economic model of disease management follows a simple equation. To produce net savings for payors, medical claims reductions must outweigh the incremental costs related to the programs. Claims reductions result from lower utilization of medical care, e.g., reductions in hospital admissions, emergency care or sick pay. In some patient groups, claims reduction potential is estimated at up to $40 \%$ of initial claims. The costs, of course, are also substantial. Medical costs induced by the program include patient education performed by medical professionals as well as medication following guidelines, outpatient consultations and check-ups that are part of the ongoing monitoring. Program costs are mainly driven by IT setup costs and staff costs for patient management.

Disease management programs can be run by payors themselves or by businesses selling these services to payors. In the latter case, programs could be paid for on a fee-per-patient basis - thus allocating only part of the risk to the payor. An alternative revenue model would be profit sharing, which basically transfers the business risk to the disease management provider.

The regulatory change recently proposed for Germany alleviates DM economics. Being refunded up to $70 \%$ of DM investments will lower the threshold of claims reductions necessary to make programs pay off for German statutory payors. On the other hand, the accreditation and auditing required to be included in the pool 
will represent a significant hurdle, necessitating investments in DM development and infrastructure. Given the potentially transient nature of this funding, programs need to be profitable in themselves as a basis for any business-building efforts.

\subsection{How to achieve impact at low running cost: some key success factors}

Sustainable DM success will depend crucially on systematic risk stratification based on objective parameters. Apart from that, highly efficient operations combined with high compliance and user convenience will be key to solving the issues that led to the failure of earlier approaches.

DISEASE MANAGEMENT ECONOMICS - EXAMPLE (SEVERE ASTHMA)*

Costs/patient/year in percent of baseline costs, Germany

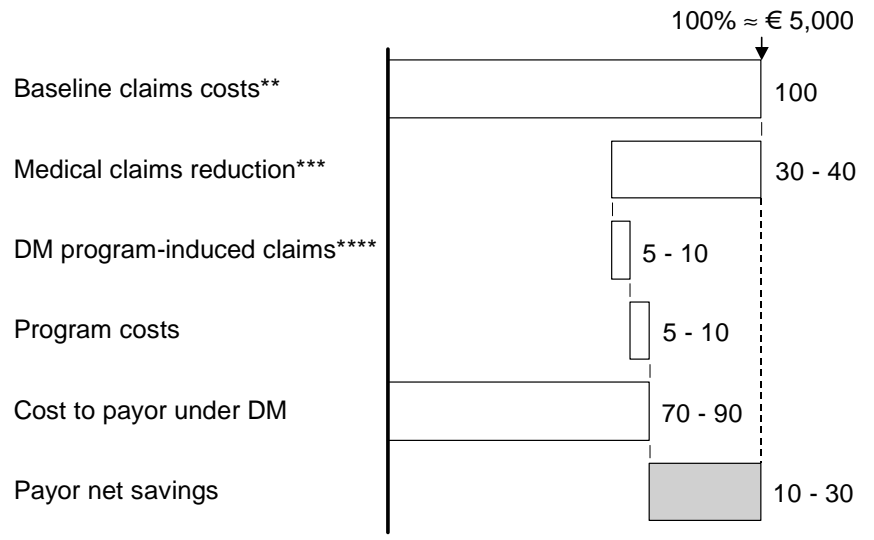

\footnotetext{
"Stage IV asthma

** Statutory payor

Hospital, emergency care and sick-pay



- Lowering the cost of programs

Achieving critical mass and full program scalability is the first prerequisite for achieving sufficiently low program costs. The high costs of developing the program development, setting up the IT and establishing a patient management infrastructure will only pay if a critical mass of suitable patients can be acquired and retained in programs long term. This implies that only relatively common conditions should be chosen. Even if, for example, you have a disease affecting every hundredth citizen, you may not end up with more than 200 participants from a population of a million citizens. Only a minority of the patients affected are at the relevant stages of the disease. Others are not suitable due to concomitant diseases that preclude participation. Attracting even $25 \%$ of the 
patients that remain after these analyses (i.e., the suitable candidates) is hard. Achieving highly efficient operations is the second cornerstone of success. In internal activity controlling and continuous improvement efforts, efficient levers have to be differentiated from activities that are not necessary to achieve patient compliance and disease control. They have to target the different available channels and e-health tools to the respective goals and patient populations. Highly standardized intervention and assigning staff with different degrees of medical qualifications (i.e., at different salary levels) to the various tasks involved are of equal importance.

- Improving compliance

E-health cannot be expected to dramatically change patient behavior from one day to the next. Yet the new technologies greatly increase the number of data points that can be acquired from patients. This makes it much easier to evaluate the current status of a chronically ill patient and quickly decide - supported by data analytical tools - on suitable intervention. It becomes possible to prioritize efforts and invest time in contacts with patients who need support or convincing that they should change their behavior patterns. A change in patients' attitude towards their own health is noticeable: patients' interest in understanding their own condition and participating in the decision on their care increases. E-health tools can support this process by boosting the efficiency of gathering information on patients. Instead of being forced to search different sources for disease-relevant information - and often trawling up dozens of articles of questionable quality in a standard web browser search - participants can be supplied with information specific to their exact situation.

- Solving data privacy and user convenience issues

Patients will of course expect resolution of data privacy issues before they are prepared to reveal sensitive medical data. They also expect user-friendly solutions: patient interfaces should ideally allow access even to users who have never used computers or the Internet before. For physicians, who have to be part of the loop, applications must be compatible with their practice IT systems. Given the heterogeneity of existing practice IT, this represents quite a challenge. A data exchange mode widely used in Germany is export from practice IT via the BDT interface, which works with the majority of practice IT systems. Moreover, physicians will not use solutions that take extra time during practice hours without giving them added value. Added value can derive from giving them access to patient data they cannot access easily, e.g., diagnostic results from other physicians, or data from hospital stays. Ideally, this involves an electronic patient record (EPR). The "Bundesknappschaft" (the German miners' health insurance fund) is already piloting "prosper-Net", an EPR connecting a hospital with a surrounding network of 50 physicians. Patients who have voluntarily chosen to join this network give their consent to the data transmission and decide which physicians may access their data. 
- Realizing payoff for payors alongside quality improvements for patients To allow payors to evidence savings, churn rates have to be lower than in the previous US approaches that failed. As opposed to the U.S., the German system offers the structural advantage for DM providers that patients do not change health insurance frequently. Particularly patients viewed as "bad risks" or with chronic disease usually stay with their health plan. Nevertheless, according to experience from long-term clinical studies, attrition rates can exceed $25 \%$ p.a. Interviews with patients have shown that patient attraction and retention depend on a number of variables, including premium accommodation in hospitals or provision of devices or materials (e.g., blood pressure devices) even more than monetary incentives. DM providers have to be perceived as independent and objective by patients. The bottom line is that patients have to be convinced that programs will improve the quality of care they receive, have impact on the medical outcome, and will not unduly inconvenience them. To answer payors' needs for fast return on investment, DM organizations should start their operations with programs that produce results quickly, e.g., congestive heart failure or asthma. To achieve this data gathering and evaluation of the pilot groups has to be meticulous.

\section{Outlook and required action}

While earlier discussions on disease management were dominated by payors and pharmacos, the new economy has produced a number of new players. Several start-ups offer health management services, from call-center or Internet-based health information services to disease management. Innovacare, MD Medicus, Gesundheitsscout 24, Arztpartner and others offer full-service DM programs. Other companies focus on technology solutions that can be integral to DM. Initially, hopes mainly rested on the start-ups. Recently, as in other industries, incumbents have been making great efforts and investments, while some start-ups are struggling to survive. Incumbents are establishing their own programs or new businesses in health and patient management, leveraging their industry experience. Medvantis Medical Services is an example of a business-building effort in the form of a spin-off. Initiated and funded by Wintherthur Insurance, the business started operations in 2000, offering consumer health information, DM and case management to private and statutory payors. Medvantis operates via call center and the Internet. Currently, Medvantis offers DM programs for diabetes, asthma and congestive heart failure, with further programs in development. Expecting to break even in 2003, it employs around 50 medical professionals, half of whom are physicians with various specialties. Payor customers include DBV Winterthur, Süddeutsche Krankenversicherung, and KKH. Programs are being evaluated together with a leading health economic institute. 
If DM finally gains a foothold in Germany, the market is substantial. If one in eighty citizens participated in a DM program at any one time at an average price of $€ 500 /$ year, DM expenditure would exceed $€ 500$ million. Given current payor expenditures of more than $€ 130$ billion, of which approximately half is spent on the 5\% most expensive diagnoses, this is still a conservative estimate of cost containment efforts by DM in high-cost populations. There may be additional potential from citizens who decide to pay for extra services from their own pockets, e.g., aging at-risk populations who want to continue physically demanding leisure activities, such as mountain biking or long-distance travel, with extra security from monitoring. Yet, given this market there can only be a few winners. We estimate that an insured population of 2 - 4 million for any one DM provider will be necessary to break even with disease management, meaning 25,000-50,000 program participants at an average price of $€ 500 /$ patient/year.

Obviously, the compensation mechanisms mentioned above that come into force from 2002 onwards will drive the development of a DM industry in Germany. First movers with the right model have a chance to establish sustainable DM products, and some incumbents could certainly be among them. Large payors will definitely attempt to set up their own disease management efforts to keep their know-how proprietary and retain eventual savings. Many small to mid-size statutory and most private payors do not reach the critical size to establish their own programs. Differentiation factors between currently active businesses will be operational excellence, program evaluation, medical know-how - and the technology applications used, all requiring significant upfront investment.

Now that lessons have been learnt from earlier failures in the fields of business and program design, the industry needs fast advances in technology development and implementation to thrive. Unmet IT requirements focus on three areas:

- IT process integration

To achieve efficiency, IT-enabled processes have to integrate the whole medical provider chain. Compatible systems, comprehensive data architectures and well-defined interface architectures are key to reaching this goal.

- Data transparency and evaluation

Transparency on the practice and processes used in e-health care has to be achieved by extensive collection and analysis of sanitized sociomedical data. Analysis and publication of such data pools will help improve both methods of risk stratification (e.g., RSA or diagnosis related groups) and quality of care. This requires norming data and data identifiers, which means driving forward on XML/XSL and DTD standardization efforts in healthcare.

- Standardization of data models for payors

Overall, standardization of data models and methodology seems mandatory, using existing object-oriented technology. Standard components could greatly reduce investment and maintenance costs, and alleviate efforts to establish disease management or other approaches towards integrated care delivery. 
Payors generally lack the very specific technological know-how and infrastructure to develop and implement the required applications on their own fast enough. The IT community will play an important role in the upcoming change and evolution of healthcare systems by supporting evolving businesses and initiatives in this field - increasing quality, efficacy and fairness. This represents a highly ethical task, and a major business opportunity to set standards and establish new markets.

The proposed changes in the German RSA to support DM efforts could make Germany a testing ground for new-generation DM that could later be replicated in other markets. RSA refunds will give DM businesses an opportunity to experiment with new technologies and work on their operations to improve overall economics and clinical effects. German citizens are much less likely to change health insurance than U.S. citizens, so returns on investment for payors could be evidenced and quantified. Advances in IT solutions will help to sustainably develop and change the health care system. Not only will the lessons learned here be watched, but some of the winners will be nicely positioned to expand their programs and applications outside Germany more quickly.

\section{References}

[ÄZ01] Ärztezeitung. Vier Jahre Disease Management - ein Konzept, das sich bewährt hat (Innovacare). ÄZ 54, 22.03.01:12; personal communications (Boehringer Ingelheim)

[BaWi00] Bakst A, Wisner CL, Kirsch J, et al. The cost of diabetes in Europe-Type 2 Study: micro- and macrovascular complications and disease progression are primary independent drivers of increased costs in diabetes. Abstract EASD 2000

[HeRu99] Heidenreich PA, Ruggerio CM, Massie BM: Effect of a home monitoring system on hospitalization and resource use for patients with heart failure. Am Heart J 1999; 138: $633-40$

[MuLe01] Munks-Lederer C, Dhein Y, Richter B, Worth H: Evaluation of a structured education program for outpatient asthmatics. Pneumologie 2001; 55(2): 84-90

[Palm00] Palmer AJ et al.: The cost effectiveness of different management strategies for Type I diabetes. Diabetologia 2000; 43: 13-26

[Schu96] von der Schulenburg et al: Medizinische Ökonomie: Kosten der Asthmatherapie nach Schweregrad. Eine empirische Untersuchung. Medizinische Klinik 10, 670

[St Vi] St. Vincent's declaration of the WHO, 1990 